\title{
BUSINESS INTELLIGENCE SYSTEMS IN SMES
}

\begin{abstract}
ADAM STECYK
University of Szczecin, Faculty of Management and Economics of Services, POLAND

e-mail: adam.stecyk@wzieu.pl

RECEIVED

ACCEPTED

JEL

CLASSIFICATION

KEYWORDS

ABSTRACT

18 January 2018

2 September 2018

C8, 012, 032

business intelligence, information systems, data collection, data estimation, ICT

The aim of the article is a presentation of the business intelligence systems for the sector of small and medium enterprises. The first part of the article contains an overview of the basic concepts related to Business Intelligence systems that allow a better understanding of the basic properties of $\mathrm{BI}$ techniques and allow their use in the SMEs. The second part of the paper contains a description of the stages of the Business Intelligence system implementation in the small and medium enterprises, using free applications available on the market. The proposed concept provides a starting point for further, in-depth reviews of building a competitive advantage in the market with Business Intelligence systems in SMEs.
\end{abstract}

\section{Introduction}

The functioning of Polish companies in the economic markets is increasingly dependent on efficient analyzing large amounts of business data and responding to changes in a dynamic environment. Companies introduce new products and services, work with a specific group of contractors and clients, as well as take advantage of new distribution channels. As a result of these activities is a growing stream of information, which must be converted to 
valuable business data. It can therefore be noted that the financial results and position in the market is dependent on the knowledge about the actual business processes and developing key economic indicators responsible for building competitive advantage and achieving business goals.

In this context, it seems that there is a great need to support decision-making processes with modern IT tools that effectively enable collecting large amounts of data, processing them into the desired structure and analyzing and reporting data in order to increase the level of effective functioning of the company. This assumption applies to large enterprises with multidimensional activities, as well as to the sector of small and medium enterprises, which carry out less complex economic processes. In other words, one must indicate such solutions, that enable the use of large amount of data, stored in company databases. In the case of the SME enterprises, which typically do not have special financial and human resources, the task of searching for relevant business associations most often remains the responsibility of the management board of the company.

\section{Characteristics of Business Intelligence system}

For several years, software for small and medium-sized enterprises is advancing the development of IT tools, known as Business Intelligence (BI). It is concluded that this concept was introduced in 1989, and defined as "a set of concepts and methodologies designed to improve business decision-making by using fact-based systems" (Hashmi, 2006, p. 6). Another definition, underlying the IT aspect, indicates that this term means "a wide range of software for the collection, consolidation, analysis and sharing of information, which enables better decision making in the organization" (Adelman, 2000, pp. 7-11). One can therefore conclude that the BI systems used by business analysts (large enterprises) or directly by the decision makers with analytical knowledge (large enterprises and SMEs ), allow the rational and effective collecting and analyzing data, significant for the main business goals of the company. The literature of the subject most often indicates the following areas of the business that can and should be supported by BI systems (Negash, 2003, pp. 78-84):

a) profitability - related to the basic objective of business conducting;

b) decision making - related to the identification and assessment of potential opportunities and threats, delivering relevant information to allow evaluation of the performed activities;

c) questioning - putting the queries that rely on the use of the built-in BI language, so one can quickly get answers to specific business enquiries.

An important concept for understanding Business Intelligence, is the maturation of the system [more about models of maturation: (Olszak, 2012, pp. 11-23). This term refers to a perfect (complete) state, to which one should strive, in the context of the use of business data. Achieving the desired state typically is associated with a specific transformation of the company, which means making various changing in the enterprise. In other words, maturity models are designed to select the direction of the development of $\mathrm{BI}$ systems in the enterprise, or to get answers to the following questions:

1. What is the place of $\mathrm{BI}$ systems in corporate strategy?

2. What are the business processes in the context of the flow of information?

3. Where are the important transportation hubs and large data sets?

4. Where are the basic economic measures (such as: cost, revenue, inventory, etc.), determining key economic indicators?

5. Who is responsible for generating the key economic indicators and decision making? 
Despite the dynamic development of Business Intelligence tools, Polish enterprises (especially SMEs) do not adequately take advantage of the proposed method and data analysis techniques. Until recently, the main reason for this was the financial barrier that allows the implementation of BI systems only to large enterprises. With the advent of cheap, commercial and even free BI tools, dedicated for SME sector, the second barrier appeared, which is associated with a lack of sufficient expertise knowledge, that allows for the rational and efficient use of business intelligence systems by policy-makers. So how should look a road map for Polish companies, and the first steps in the area of Business Intelligence? The answer to this question can be found in the dual-purpose activities. First, in choosing/buying such BI tools, which will be characterised by:

a) flexible report creation without the expertise and technical knowledge;

b) the ability of fast connecting to any data source (spreadsheets, network and desktop databases, text files, Web pages, social networking sites, etc.);

a) building up analyses on demand in real time;

b) an intuitive and simple interface to the data visualization;

c) security in sharing the reports and data protection.

The second component is to gain by decision makers the key competences (knowledge) related to the data analysing. The most important areas should include knowledge about:

- ability to get data, from a variety of sources,

- the relational data model (structure and how to store information),

- basic analytical techniques in the context of building a key economic indicators,

- dynamic reporting with built-in visualization techniques (charts, maps, tables, KPIs etc.).

\section{Business Intelligence tools for SMES}

The most popular analytical program used in enterprises is the spreadsheet, which advanced tools, in particular, pivot table, allow to aggregate data and create basic reports on operational and tactical dimension of the functioning of the company. This is not a database tool, the companies use other systems (financial, accounting, human resources, resources management, inventory, etc.) to collect business information. From the point of view, it is important that the data collected through these systems can be saved (exported) in database format, or in spreadsheet format, which will allow decision makers to prepare advanced business intelligence analysis. At this point one should therefore indicate the main steps and tools for the use of BI techniques in small and medium-sized enterprises:

1. Identification of the sources and the nature of information in the enterprise - database identification and how data is stored in information systems.

2. Preparing data in tabular form - export (save) data and adjust their structure (table headers, data types, delete unnecessary records, etc.). At this stage, analysts/policy makers can use the free add-in program for Microsoft Excel spreadsheet, which is Power Query, allowing the appropriate data preparation. The second option might be using the Microsoft Power BI (free business intelligence tool) and the built-in Query Editor (Query).

3. Preparing data model - a combination of tables and relations that contain specific data (normalization of the project). At this stage the analyst must have a basic knowledge of relational data model that enables 
appropriate data structure. The data model can be built by using the free add-in for Microsoft Excel spreadsheet which is Power Pivot or directly in Power BI.

4. Business Analytics - aggregating data, calculations of specific values, the creation of new measures and hierarchies, adding and/or connecting specific fields/tables (for example, a table that contains a date (year, quarter, month, day), allowing for a detailed analysis Business Analytics can be done in the Power Pivot or directly in Power BI. At this stage the analyst requires knowledge of basic techniques and analytical formulas (aggregating functions, columns, and calculated fields, key indicators, DAX, etc.).

5. Visualization and the preparation of reports - graphical presentation of data (dashboards) using charts, diagrams, maps, tables, text values, etc. (two free add-ons to a Microsoft Excel spreadsheet: Power View and Power Map or visualizations in Power $\mathrm{BI}$ ).

6. The report sharing and the data safety - availability and editability of the prepared reports.

7. Scenario of the presentation and interpretation of the reports (storytelling) - using the interactive features within developed reports, enabling multi-level presentations (individual categories, using Power Bi Quick Insight, automatically detecting existing associations between the data, which are not always visible to the analyst).

8. Advanced analysis in Power BI - using expert tools to create enhanced solutions: Advanced SQL functions, a DAX formulas, prediction analysis using Azure services and $\mathrm{R}$ language, display and update results reports in real time, etc.

Business intelligence development steps in the sector of small and medium-sized enterprises constitute a starting point for building a sound business strategy based on economic data collected in the company. Business intelligence reports can be used to increase the level of efficiency in many areas of business. The most important of them include:

- analysis (analysis of costs and revenues),

- production planning (the efficiency of processes and resources),

- quality management,

- analysis of the efficiency of the employees,

- optimization of inventory,

- analysis of the supply chain.

\section{Conclusions}

Efficient management and making the right business decisions requires knowledge on the processes coordination and resource configuration in the enterprise. In order to increase the level of efficiency of company functioning, it is necessary to use Business Intelligence solutions that are available on the market. Regardless of whether the size of the enterprise, a manager working in a dynamic environment, should use the BI techniques that are a big help in resolving issues related to one of the biggest challenges of modern management - the unlimited amount of information. The proposes use of business intelligence tools can be an important part of building a competitive advantage in the market and a starting point for searching for new, more effective and better quality business models for small and medium-sized businesses. 


\section{References}

Adelman, S.M. (2000). Data Warehouse Project Management. New York: Addison-Wesley.

Hashmi, N. (2006). Business Information Warehouse for SAP. Roseville: Prima Publishing.

Negash, S.G. (2003). Business intelligence. New York: Ninth Americas Conference on Information Systems.

Olszak, C.M. (2012). Analiza i ocena dorobku naukowego z zakresu Business Intelligence. Katowice: Wydawnictwo Uniwersytetu Ekonomicznego.

Cite this apticle aS: Stecyk, A. (2018). Business Intelligence systems in SMEs. European Journal of Service Management, 3 (27/2), 409-413. DOI: 10.18276/ejsm.2018.27/2-50. 